\title{
SOBRE LA LIBERTAD SINDICAL EN EL CHILE DE LA POSGUERRA
}

\author{
WILLIAM THAYER ARTEAGA \\ Pontificia Universidad Católica de Chile \\ 1. "SE CIERNE LA TORMENTA"1.
}

1.1. En 1939, mientras expiraba la guerra civil española y se anunciaba el estallido de la Segunda Guerra Mundial, el joven profesor Eduardo Frei Montalva, enseñaba el Código del Trabajo de 1931 a sus alumnos de tercer año de Derecho en la Universidad Católica, entre los que me contaba, como "niño nuevo", recién llegado de Valparaíso. Poco después (1942-1946) debí parcialmente profundizar esos temas, no por exigencias académicas, sino como funcionario de las Comisiones Mixtas de Sueldos, nuevos tribunales especiales del trabajo a los que ingresé por un concurso, que no pensaba ganar. Recién había perdido. "por secretaría" una opción mucho menos exigente para ingresar a la Dirección de Aeronáutica. Esos años como funcionario del Ministerio del Trabajo, me hicieron impensadamente especialista en la legislación laboral que regía a los empleados particulares ${ }^{2}$.

\section{2.- LA ESTRATEGIA DE LOS EMPLEADOS PARTICULARES.}

2.1. Interesa recordar que el sector de los empleados particulares se alejó del sistema de "conflictos colectivos" con que negociaban los obreros, conforme al Código de 1931, pues prefirió acogerse a la estabilidad y seguridad de una ley especial. Esta, llamada de " $M e$ joramiento económico de los empleados particulares"3, establecía para ellos sueldos vitales, reajustes, aumentos voluntarios, promociones, ascensos por antigüedad, asignaciones familiares, indemnización por años de servicios y subsidio de cesantía. En cambio, su art. 40, solo les permitía presentar pliegos de peticiones económicas transcurrido un año desde el último reajuste legal. Como los reajustes eran anuales, los empleados quedaron al margen del sistema de conflictos colectivos económicos vigente para los obreros. Una manera algo críptica de legislar, que no se originó por inadvertencia, sino por una consciente y muy debatida preferencia gremial acogida por el Gobierno.

2.2. Esta experiencia funcionaria me puso en contacto con uno de los problemas peculiares de nuestra evolución laboral: la diferencia entre empleados particulares y obreros, socialmente más importante que la de empleados públicos y particulares. Entonces había aproximadamente 10 obreros por cada empleado particular. Las asociaciones de empleados (UECH, FIEP, CONEP, CEPCH, ANES, ANEF, JUNECH), mantenían variables grados de cercanía con las de base obrera (FOCH, CGT y CTCH). Esta había conseguido la he-

Palabras usadas por Winston Churchill como rótulo para el tomo I de su historia de la 2a Guerra.

2 Ley 7295, 1942, refundió las leyes 6020 (1937), 7064 (1941) y 7280 (1942).

3 Ley 7295, de 1942, que refundió las leyes 6020, 7064 y 7280, de 1937, 1941 y 1942. 
gemonía en diciembre de 1936 , apoyada por comunistas y socialistas, justo cuando para los empleados particulares entraba a regir la citada Ley $\mathrm{N}^{\circ} 6.020$, origen de la $\mathrm{N}^{\circ} 7.295$. En 1953 se creó la soñada Central Única de Trabajadores (CUT), a la que imperativos nacionales e internacionales de libertad sindical, le impusieron -teórica y prácticamente- sustituir el calificativo "Única" por "Unitaria", conservando la sigla CUT hasta hoy. Su efectiva representatividad no es tema de esta exposición.

2.3. Recordemos que el sistema de federaciones y centrales funcionaba al margen de reconocimiento legal, pero con universal tolerancia política, siguiendo en ello una constante del movimiento sindical internacional desde la abolición de la Ley Le Chapelier (1791) y sus ecos fuera de Francia. Cabe tener presente aquí que los empleados -los "débiles, apatronados y pequeño-burgueses" trabajadores de los años 1930 y 1940- fueron ganando en número y fuerza, mientras el proletariado en cuanto tal perdía fuerza e identidad, hasta desaparecer, como consecuencia del traspaso a las máquinas del esfuerzo físico, de la educación, la capacitación y el ahorro -forzado o voluntario- que permitieron el avance social y las mejores remuneraciones de los obreros calificados. Finalmente, se fundieron obreros y empleados en una sola categoría legal de "trabajadores" 4 .

\section{ESTATUTO DE LOS TRABAJADORES DEL COBRE.}

3.1. El cinturón de hierro que prohibía legalmente las federaciones, confederaciones y centrales de sindicatos obreros lo rompió el Estatuto de los Trabajadores del Cobre, dictado para regir desde 1956 las relaciones laborales entre empleados, obreros y empleadores o patrones de la Gran Minería del Cobre. Su raíz fue la Ley $N^{0} 11.828$, de 3 de mayo de 1955 , denominada de Nuevo Trato a la Gran Minería del Cobre. En ella se reconoció legalmente la Confederación Nacional de Trabajadores del Cobre (CTC), que reunía a los sindicatos industriales (obreros) y profesionales (empleados) de esa rama principal de la industria minera. Los estatutos de la CTC los protocolicé en la notaría de Herman Chadwick Valdés, el 26 de octubre de 1956. Los dirigentes nacionales de la CTC, encabezados entonces por Eduardo Delfín, Rafael Albornoz, Rubén Meneses, Eduardo Cuturrufo, Gustavo Cordero, Pedro Tapia, Alejandro Rodríguez, Edmundo Callejas y varios más, también hablaban con orgullo de la "Confederación de Trabajadores del Cobre con personalidad jurídica", característica que no solo le otorgó un significado especial como entidad representativa, sino un poder sindical y económico envidiable. Su administración se regularizó y contó con un fuerte financiamiento ajustado a la Constitución, la ley y sus estatutos. Más que cualquier otro gremio, los sindicatos de la Gran Minería del Cobre iban a cambiar la historia laboral de Chile cuando su "estatuto de excepción" en temas decisivos y esenciales se generalizó.

3.2. Nunca supe cómo llegué en 1954 a la asesoría jurídica de la más fuerte organización sindical de Chile, después de haber asumido en 1947 providencialmente la asesoría de la también poderosa Confederación de Sindicatos de Empleados del Banco del Estado,

4 Decretos leyes 2.200 (1978); 2756 y 2758 (1979). 
como relaté en otra publicación ${ }^{5}$. La cuestión parece un detalle personal, pero es ilustrativa. Imagino que confluyeron varios factores. Desde luego, por aquellos años (1954 ó 1955) correspondía dirigir la Confederación -según sistema de turnos- a la Zonal Chuquicamata, donde había una interesante base de la ASICH, establecida en tiempos del Padre Hurtado. Sus líderes Rafael Albornoz, Juan Argandoña, Pedro Tapia y otros me conocían y distinguían por mi colaboración con él. También pesaba el hecho que, en mi calidad de abogado de los trabajadores del Banco del Estado, atendía profesionalmente en la oficina que me proporcionaba esa entidad gremial ( $4^{\circ}$ piso de la entonces Sucursal Huérfanos del Banco del Estado, ex Caja de Crédito Hipotecario), a muchos gremios, sindicatos e instituciones sociales. Se ganaba poco, pero se hacía mucho. Mi mujer y mis hijos sufrían agudas estrecheces, mientras mi generación veía nacer lentamente un nuevo mundo sindical.

\section{GREMIOS Y SINDICATOS. LAS CAJAS DE COMPENSACIÓN.}

4.1. A mediados de los cincuenta, Eugenio Heiremans, Jorge Matetic, Sergio Silva Bascuñán y Jorge Sánchez me habían encomendado organizar la Caja de Compensación de Asignación Familiar en el gremio metalúrgico (ASIMET), a semejanza de la ya exitosa Caja de la Cámara de la Construcción. Este contacto con el mundo empresarial y obrero a la vez en los fuertes sectores metalúrgico y de la construcción, más la asesoría de los bancarios, de los trabajadores del Cobre y las responsabilidades que conservaba de mis contactos con la ASICH, mantenían en plena actividad la oficina que desde 1947 me proporcionaba la Confederación de Sindicatos del Banco del Estado. La compartíamos con mis inseparables amigos y colegas Ramón Luco y Ernesto Yávar. Más tarde me integré a la oficina encabezaba por don Carlos Vergara Bravo, al que nos sumamos con Fernando Castillo Infante y Gustavo Lagos.

A comienzos de 1952 , por la enfermedad del R.P. Hurtado 6 debí trasladareme al local de la ASICH, en calle Alonso Ovalle al llegar a San Ignacio Más tarde,1954, fallecido el Padre Hurtado, me pidieron la renuncia a la ASICH y a la representación para América Latina de la CISC7. Asumí entonces como subgerente organizador y luego como gerente general, la conducción de la Caja de Compensación de Asimet, conservando solo las asesorías sindicales ajenas al citado gremio metalúrgico.

4.2. Entre tanto, instalado en la Presidencia de Chile por segunda vez, don Carlos Ibáñez, mi vecino, amigo, presidente de la ANES (Asociación Nacional de Empleados Semifiscales) y de la JUNECH (Junta Nacional de Empleados de Chile), Eduardo Long Alessandri, como buen sobrino de Alessandri Palma, quedó cesante y me pidió nos asociáramos, por un par de horas al día, porque necesitaba abrir una oficina profesional como abogado sindicalista y él estaba algo fuera de "training" debido a sus largos años de empleado semifis-

5 Thayer Arteaga, William. Segunda fila. Santiago, Chile: Editorial Jurídica Ediar ConoSur Ltda., 1987, pp. 23-25.

6 Thayer ARteaga, William. El Padre Hurtado y su lucha por la libertad sindical. Santiago, Chile: Editorial Andrés Bello, 2000 , p. 506.

$7 \quad$ Ibid., pp 222 y 55 . 
cal y dirigente sindical ${ }^{8}$. Long, socialista, vecino y viejo amigo también, asumió la asesoría de la CUT y de muchas de sus federaciones afiliadas, con directivas marxistas en su gran mayoría.

4.3. De esta manera, con Long o sin Long, las asesorías sindicales en que me vi vinculado o comprometido, como hombre "uno", como hombre "dos" o como consultor en materias laborales o de seguridad social, abarcaban a casi todo el espectro sindical de Chile. Por sus lado, la Caja de Compensación "Asimet" y sus congéneres mantenían, como organismos de administración bipartita, contacto natural con el mundo sindical y de las empresas en materias de beneficios familiares y de seguridad social. Se vivía un mundo atípico y fascinante. A los trabajadores y a las empresas poco importaba el color político de los asesores legales, mientras se respetara el Derecho. Para mí no había mucha diferencia entre llegar con Hugo Méndez, asichista, presidente del sindicato industrial INSA, y mis inseparables amigos Ernesto Yávar y Ramón Luco, a discutir con el gerente José Luis Claro, el conflicto de la empresa INSA; o a la asamblea sindical de Chuquicamata, o a las oficinas de Confederación de Trabajadores del Cobre, o con Eduardo Long y Bernardo Araya a la asamblea que debía aprobar -o rechazar- la fórmula de arreglo del difícil conflicto obrero en la Fábrica Said de Quillota. En cambio, diferente cosa era llegar en 1965 como Ministro del Trabajo a la Plaza de Lota, y enfrentar una fiera concentración obrera comunista, preparada para comerse vivo al representante del Gobierno "burgués" del señor Frei Montalva, que había derrotado en 1964 a Salvador Allende, con votos de la derecha.

4.3.1. En mi caso personal, con mi "pedigree" de abogado sindicalista; mis contactos por décadas con sindicatos, gremios y trabajadores, incluyendo un par de viajes al oscuro mundo de las galerías subterráneas y submarinas de Lota y Schwager, preparando la exitosa aprobación de la "ley de lámpara a lámpara", generaban una cierta consideración profesional y humana, bajo la alharaca de diferencias partidistas. Estas que no encajaban en los ámbitos de la seguridad social ni en los sindicatos de la Gran Minería del Cobre. No era mucho, pero era algo; quizá más que "algo": un síntoma o anuncio del siglo XXI, que vendría pocas décadas después.

4.4. En suma, desde 1942, en que se inició mi labor como funcionario de las Comisiones de Sueldos, pasando en seguida por el mundo inmenso del Padre Hurtado (19361952 , período de su misión en Chile), al que luego me referiré. Volví "después de Once" -expresión que algunos usaban por alusión al 11 de septiembre de 1973- a mis labores académicas en la UC. Pero la vorágine siguió: fui nombrado coordinador de la Asociación de Mutuales reguladas por la Ley $N^{\circ} 16.744$. En 1974, el Consejo Ejecutivo de UNESCO me eligió como miembro en reemplazo de Pablo Neruda, fallecido de cáncer diez días después del "Once". Más tarde, integré el directorio de DESCO y el directorio fundador de Provida; reasumí la asesoría de los Trabajadores del Cobre; en 1981, entré al Consejo de

\footnotetext{
Su otra opción profesional, nuestro común amigo Carlos Domínguez Casanueva no pudo acompañarlo.

9 Destinada a considerar como trabajado el tiempo de desplazamiento del minero dentro de las galerías.
} 
Estado, acepté la Gerencia General de la Editorial Jurídica, cargo que dejé en 1990, cuando fui designado senador institucional en calidad de ex rector universitario. Viví, pues, una especie de larga y personal posguerra, iniciada con mi graduación y matrimonio en 1945 y prolongada hasta estos inicios del siglo XXI, con un escenario nacional y mundial que fue cambiando veloz y fundamentalmente. Vale la pena, por eso, echar una mirada al contexto internaçional de la evolución nacional que he tratado de reseñar.

\section{EL CONTEXTO INTERNACIONAL}

5.1. El siglo XXI debiera ser mirado como un escenario de grandes riesgos, pero de mejores opciones. Al menos, en cuanto a relaciones laborales ofrece efectivas oportunidades de las que careció el siglo XX, tan ensuciado por el odio y el resentimiento que dominó el mundo asociativo sindical entre 1919 y 1991, fechas que enmarcan el nacimiento de la Tercera Internacional (fundada por Lenin en Moscú), y la extinción de la Unión Soviética, signo y símbolo del fracaso de las "democracias populares".

5.2. La citada Tercera Internacional, o Komintern, desde 1919, decidió utilizar los sindicatos como correas de trasmisión del pensamiento y el quehacer revolucionarios, que debían destruir el Estado burgués e implantar la dictadura del proletariado. Este sueño, que costó, en definitiva, unos 100.000 .000 de muertos ${ }^{10}$, creó en todas partes un dilema: apoyar al sindicato por ser una legítima herramienta de promoción de los trabajadores, aunque implicara al mismo tiempo, favorecer una herramienta revolucionaria que, según los propósitos de la Tercera Internacional, debía destruir las empresas privadas y la economía fundada en la propiedad privada, para instaurar la dictadura del proletariado.

5.3. Ahora, en este amanecer del siglo XXI, el escenario es muy diferente. La violencia se hace presente en forma de un terrorismo atroz (Torres Gemelas, Madrid) y de conflictos raciales e históricos, principalmente en el Oriente Medio. Pero hay factores que justifican una actitud esperanzadora en la inmensa masa de la población pacífica del planeta. Miles de millones de seres humanos trabajan, gozan, sufren, triunfan y pierden, pero anhelan entendimiento y paz, y no piensan en conquistas guerreras, como ocurría en tiempos del Antiguo Testamento, de Alejandro el Grande, Aníbal, Gengis Khan, Hitler o Stalin. La Segunda Guerra Mundial y el balance de sus causas y sus infamantes secuelas impidieron la Tercera Guerra -la nuclear-, que muchos temían. Se dio paso, en cambio, a una cultura donde faltan todavía conductas educadoras y pacificadoras, pero, al menos, se rechaza la guerra de conquista y se espera hallar caminos para la paz. Estudios serios demuestran que entre las décadas 1960 y 1990 el crecimiento del producto en el mundo fue de entre 6,5 a 21,8 billones de dólares (de 1985), o sea, aumentó a tasa de 4\% anual, más del doble que el aumento de la población. Esta creció de 3.000 a 5.200 millones, o sea a tasa de $1,8 \%{ }^{11}$.

10 COURTOIS, Stêphane. El libro negro del comunismo. Madrid, España: Editorial Planeta-Espasa, 1998, p. 18

11 ThaYer ARTEAga, William "La negociación colectiva en Chile y los desafíos empresariales y sindicales de la nueva economia", en: V.V.A.A. la negociación colectiva en Chile: $y$ sus perspectivas ante las reformas laborales y los desafios de la nueva economia. Santiago, Chile: Editorial Gestión, 1997,672 p. 
Hay, pues, una falla en educación y justicia social. Por su lado, el Tratado de Versalles (1919), que selló la Primera Guerra Mundial, introdujo como su parte XIII la institución de la OIT y marcó, quizá para siempre, en la conciencia de la humanidad que no habría paz internacional sin justicia social. Igualmente planteó el problema tremendo del desarrollo y la equidad: ¿Qué debemos priorizar la equidad o el crecimiento? ¿Es posible condicionar el crecimiento a la mantención de la equidad en la distribución de la riqueza? Me inclino a pensar que los países avanzan como una oruga y no como un convoy ferroviario: primero arranca la cabeza, luego el cuerpo se estira, más tarde se contrae, y, después, la cabeza vuelve a avanzar. Por ello, no debemos frenar la cabeza para que no se distancie de la cola, sino proteger la cola, para que no se quede atrás y dificulte el avance del cuerpo social.

5.4. Interesa recordar cómo repercutían en Chile los cambios y acontecimientos internacionales, felices o desgraciados. Para no ir demasiado atrás, cinco años después de entrar en vigor el DFL N 178 de 1931 (primer Código del Trabajo), mientras los empleados particulares daban una gran batalla gremial por la aprobación de la Ley $\mathrm{N}^{\circ} 6020$-promulgada finalmente el 8 de febrero de 1937-y los obreros preparaban la puesta en marcha de CTCH (Confederación de Trabajadores de Chile), estallaba la Guerra Civil Española (1936-1939), prolongada y universalizada en la Segunda Guerra Mundial (1939-1945). A ella siguió la inquietante posguerra, con sus desconfianzas, amenazas y nuevas guerras: Corea, (19501953); crisis de los misiles Kennedy-Kruchev (1962); Vietnam, (1961-1975). Estos sucesos se confundían con espectaculares progresos en ciencia y tecnología (radar, satélites artificiales, astronautas, viaje a la Luna, informática, internet), que habían creado un mundo nuevo, de insospechadas perspectivas, aunque envenenado por el terrorismo, la droga, odios raciales y religiosos, corrupción y pobreza. El papa Juan XXIII, por su parte, convocó al Concilio Vaticano II (1963-1965), que clausuró Pablo VI. Este máximo torneo de la Iglesia Católica modificó su estrategia apostólica, urgida por la necesidad de creencias religiosas.

\section{SEGUNDA FILA. LA HISTORIA NACIONAL Y EL PADRE HURTADO}

6.1. En 1987 publiqué un breve recuento de mis experiencias y testimonios entre 1925 y 1973. Cerré esa crónica con el bombardeo de La Moneda, a mediodía del 11 de septiembre de 1973, ignorando muchos de los antecedentes que condujeron a ese dramático desenlace y sin perspectiva alguna para evaluar el significado y proyecciones de lo que estábamos observando. Sin embargo, se afirmó en mi conciencia la idea de que había vivido hasta entonces un período de cambios trascendentales, aunque ordinariamente "en segunda fila" -o sea, como testigo privilegiado más que como protagonista-, pero cerca de los hombres y situaciones que marcarían la historia de Chile. Transcurridas más de tres décadas desde el momento en que terminó aquella crónica (1973), juzgo de interés comentar, ampliar o corregir lo que la perspectiva del tiempo me aconseja.

6.2. En mi caso particular, la mejor perspectiva para enjuiciar esa multifacética experiencia de vida no me la proporciona principalmente el transcurso del tiempo, sino la maduración de mi propio juicio, fruto de muy variadas circunstancias, de la enseñanza de 
mis padres -que en la vejez uno valora mejor-, el permanente intercambio de opiniones con mi esposa y la cercanía de sacerdotes excepcionales: el primero de todos, Alberto Hurtado. Su santidad, progresivamente internalizada en la conciencia de los chilenos, se ha constituido en la más poderosa palanca que presiona por elevar el nivel moral de nuestras conductas públicas y privadas en los inicios de este siglo XXI. Por lo mismo, su beatificación primero y canonización, después, me han obligado a releer y repensar lo que significaron en mi vida su palabra y su ejemplo, sin duda mayores después del 18 de agosto de 1952, que antes de esa fecha. Son los poderes misteriosos, pero evidentes, de la santidad.

6.3. En "Segunda Fila" me refiero repetidas veces a él, a propósito de mis quehaceres universitarios y de la Acción Católica y junto a otros conductores espirituales, a los que tanto debo, como: el asesor nacional de la ANEC, don Jorge Gómez; don Pancho Vives, prorrector de la Universidad Católica y profesor de Introducción al Estudio del Derecho, del que fui ayudante durante seis años, y monseñor Manuel Larraín, obispo de Talca, asesor nacional de la Acción Católica y el más entrañable amigo del padre Hurtado ${ }^{12}$. En ese ensayo, me refiero al padre Hurtado como santo, apóstol y sabio ${ }^{13}$, literalmente, casi los mismos conceptos, que -sin atender a lo antes escrito-- utilicé como subtítulo de otra obra dedicada a él14.

6.4. Al ilustre y santo jesuita lo conocí a comienzos de 1937 , en un retiro espiritual para universitarios porteños. Nació entonces una amistad que no había de terminar jamás, lo cual quizá ocurra a todos los que fuimos sus discípulos. Cambió de forma esa amistad con su fallecimiento, el 18 de agosto de 1952, pero siguió igual o mejor, porque desde ese momento no fue necesario pedirle audiencia.

6.5. Justo un año más tarde, de conocer al P. Hurtado, cumplí la primera etapa de mi servicio militar en el Regimiento Maipo, de Playa Ancha, bajo las órdenes del teniente instructor Augusto Pinochet Ugarte. Al terminar ese primer período, mi familia se trasladó a Santiago, dejando Viña del Mar, donde durante varios años vivimos en la Avenida Libertad, al llegar a 4 Norte, en una casa contigua a la de la familia Allende Gossens. Ahí me acostumbré desde niño a admirar la belleza y encanto de Laurita Allende -amiga de mis hermanas mayores- y a observar, sin mayor atención, como se paseaba preparando exámenes, su hermano, el joven estudiante de medicina, Salvador Allende.

6.6. Ya instalada mi familia en la capital, la Divina Providencia quiso que fuera alumno -como ya dije- de Eduardo Frei Montalva, que por esos años debutaba como promisorio profesor de Derecho del Trabajo. En los años 39 y 41 ocupé varios cargos directivos juveniles en la $\mathrm{ANEC}^{15}$. Mientras la Unión Soviética y los Estados Unidos se aprestaban para

\footnotetext{
12 Thayer Arteaga, William, Segunda... (n. 5), p. 16

13 Ibid., pp. 29, 31 y 39

14 ThaYer ARTEAGA, William. Ni politico, ni comunista. Sacerdote, sabio y Santo. Santiago, Chile; Ediciones Olmué, 2004, passim.

15 Asociación Nacional de Estudiantes Católicos.
} 
entrar en la Guerra Mundial ${ }^{16}$, fui elegido presidente del Centro de Derecho, cargo que pronto debí abandonar para asumir la presidencia de la juventud de la Acción Católica, en los mismos días en que el padre Hurtado -hoy san Alberto Hurtado- era nombrado asesor nacional de esa rama.

6.7. El fallecimiento de mi padre en 1942 me obligó a dejar la agobiadora y fascinante tarea de colaborar día a día con ese viento impetuoso de gracia y acción que era el padre Hurtado. El ingreso a un trabajo rentado en la Administración Pública; la redacción de mi memoria de prueba, el examen de licenciatura, mi titulación como abogado, mi matrimonio con Alicia Morel, el advenimiento de los primeros hijos, algunos años de práctica de la abogacía con un prócer conservador ${ }^{17}$ y los comienzos de la docencia universitaria, llenaron el período 1942-1947, mientras en el mundo, con el estallido de dos bomba atómicas, terminaba la Segunda Guerra Mundial, se creaban las Naciones Unidas y se iniciaba la tensa y larga posguerra. No eran tareas sencillas la reconstrucción de Europa, la convivencia pacífica entre vencedores y vencidos y, sobre todo, la relación entre los propios vencedores: Estados Unidos y Europa Occidental, por un lado, y la Unión Soviética y sus satélites, por otro.

\section{REFLEXIONES TREINTA AÑOS DESPUÉS DE “SEGUNDA FILA.”}

7.1. Mi vida no se caracterizó por perseguir desde niño una actividad determinada o un cargo concreto. Ella se fue estructurando por opciones y ocasiones que me empujaron hacia quehaceres apostólicos, filosóficos, universitarios, laborales y profesionales muy variados.

7.2. Los cuatro años consagrados al mundo de los empleados particulares equivalieron a un doctorado. Los "white collar" eran en Chile, a mediados del siglo XX, envidiados por los obreros, porque gozaban de sueldo vital y asignaciones familiares tres veces superiores al salario mínimo y las asignaciones familiares de los obreros. Además, tenían consagrados en la Ley $\mathrm{N}^{\circ} 7295$ su indemnización por años de servicios de un mes por año, un sistema anual reajustes legales y, como vimos, otros beneficios. Por si fuera poco, su "estatus" legal y social era mejor. Puesto que sabían leer y escribir, podían ingresar de "junior" a una empresa y ascender hasta gerente general o presidente. Por la inversa, el obrero estaba condenado a ser un miembro de "clase proletaria", condición que lo enaltecía como agente activo de la revolución social, pero estancaba sus esperanzas de promoción social y ciudadana. Los empleados no eran revolucionarios, aunque muchas veces revoltosos y les gustaba jugar a la revolución, en la que no creían. En la dictadura del proletariado ellos no tendrían parte ni protagonismo. En términos de la doctrina social de la Iglesia, favorecían la "redención del proletariado", o sea, a la desaparición de la condición inhumana de proletario mediante la educación, la capacitación, el acceso al ahorro y a los cargos superiores en la empresa. Su sindicalismo no era para ellos una herramienta esencial, sino en las grandes empresas. El

16 Alemania invadió la URSS en junio de 1941, y los japoneses bombardearon Pearl Harbor en agosto.

17 El diputado Enrique Alcalde Cruchaga. 
sindicalismo obrero, con su predominio marxista abrumador, los miraba como pequeños burgueses, traidores a la revolución Además, el sindicato industrial obrero, renunciando a la libertad, les daba la seguridad de financiamiento por cuotas que obligatoriamente descontaba la empresa a todos los obreros de ella, $y$, asunto de interés e importancia, el sindicato recibía, adicionalmente, una cantidad igual al 3\% del monto de los salarios, a título de participación en las utilidades. Otra cantidad igual favorecía a los obreros individualmente

7.3. Pero desde mediados del siglo XX los cambios fueron cada vez más ostensibles. El proletariado, como clase o fuerza orgánica, perdió su seducción hasta extinguirse, porque se evidenció sin destino, por varias causas. Desde luego, fue decisivo el derrumbe primero moral y luego político del país estrella de la dictadura del proletariado: la Unión Soviética. Además, en Chile se generalizó en 1978 la eliminación de diferencias entre empleados y obreros para la aplicación del derecho individual del trabajo, que ya se había establecido para ciertos fines específicos ${ }^{18}$. En 1979, se amplió tal asimilación a todos los sindicatos, negociaciones y contratos colectivos de trabajo. Por otra parte, la unificación legal de empleados y obreros elevó automáticamente el promedio de escolaridad en las antiguas asambleas de obreros, aparte de la mayor cobertura que se fue produciendo en la educación básica, media y superior. Los sindicatos, nominados 1 y 2 , reemplazaron en muchas empresas a los sindicatos industrial u obrero, y profesional o de empleados. Se fueron homogeneizando beneficios legales y las formas de negociación. El analfabetismo se redujo a 5\% comienzos del siglo XXI y el esfuerzo físico se traspasó en gran medida a las máquinas. Prácticamente, el mundo laboral de comienzos de este siglo XXI, se parece más al de los empleados de los años sesenta y casi no conserva huellas del mundo obrero de aquella década. De las asambleas de obreros proletarios de los años cuarenta a sesenta solo sobreviven algunos hábitos fantasmales. La educación, la libertad sindical y la cultura ganaron también "su guerra de las Galaxias". El marxismo dejó de dominar el mundo laboral, que hoy es en Chile, de preferencia, socialdemócrata, humanista cristiano o independiente. El grueso de los socialistas se ha "renovado", abandonando el marxismo-leninismo, y el Partido Comunista considera un éxito si alcanza un respaldo nacional de 5 a $7 \%$. Los trabajadores poseen, en su mayoría, casa (generalmente con deuda hipotecaria), bienes durables y opciones para una indemnización por años de servicios. Sus fondos de ahorro previsional (AFP) alcanzan varias decenas de miles de millones de dólares y constituyen fuente principal de inversión en nuestra economía. El trabajador conoce la experiencia de poseer capitales y comprende -no muy claramente aún- que tanto sus exigencias como las posibilidades de la empresa y del país, están científica, técnica, social y moralmente condicionadas a la eficiencia del trabajo productivo y que los excesos se pagan en desempleo. Aunque no hay plena claridad, se presiente por muchos que el ahorro de los trabajadores en fondos previsionales compite con el del Estado o el de las empresas. Panorama distante años luz del que se vivía cuando se elaboró el primer proyecto de Código del trabajo (1921) o rigió el primer compendio de leyes laborales que se conoció con ese nombre (1931).

18 Por ejemplo, ley 16.455, de 1956, sobre terminación del contrato de trabajo; ley 16.625, de 1967, sobre sindicación campesina, y ley 16.744 , de 1968, sobre seguro social de accidentes del trabajo y enfermedades profesionales. 
7.5. Por lo mismo, no es de extrañar que las huelgas casi han desaparecido en las empresas privadas y que el grito revolucionario de los siglos XIX y primera mitad del XX "Lo que tú ganas me lo quitas a mí", tiende a sustituirse paulatinamente, aunque todavía con insuficiente internalización, por el de quienes se sienten interpretados por la conclusión: "Si tú no ganas, no gano yo". Esto se vive y se cultiva, sobre todo, en el alma de los trabajadores de las empresas sólidamente establecidas, que desarrollan una renovada política de relaciones con su personal.

7.6. Con todo, aún no se logra -salvo excepciones- llegar a la evidencia psicológica y moral de trabajar "en lo propio". Sentirse trabajando en lo propio, cuando media un contrato de trabajo y no de sociedad, es difícil, pero no imposible. En la norma, tanto el trabajador común, como el ejecutivo y el jefe de empresa, cuando no se sienten laborando en algo propio, en su empresa, limitan el esfuerzo y bajan la productividad. Conozco alguna empresa que, hace pocos años, en Santiago de Chile, triplicó la producción y las remuneraciones, con el enorme aumento de su productividad, generado desde que los trabajadores tomaron conciencia de trabajar en "lo propio"; o sea, se convencieron de que la empresa en que trabajaban era efectivamente "su empresa", no la empresa del empleador. Y para esto no se requería artificios de propaganda, sino transparencia de un sistema regularmente participativo en lo económico y en lo moral ${ }^{19}$. Es curioso anotar cómo, por complejas circunstancias que no es el momento de examinar, algunos deportes -el fútbol, desde luego- consiguen una moral de pertenencia y participación en los socios del club al que pagan cuotas, que no se da en los trabajadores de la empresa que los remunera. Más aún, clubes deportivos del arraigo popular -como Colo-Colo, la U de Chile y otros- han adoptado la estructura de sociedad anónima, que los sacó de la quiebra para llevarlos a una condición, a veces, de categoría mundial ${ }^{20}$.

7.7. Cuatro problemas, sin embargo, deben examinarse, porque se levantan como obstáculo -real o aparente- al objetivo de mirar la empresa como una "comunidad humana de trabajo".

7.7.1. El primero, es que todo lo dicho debe evaluarse en el contexto de un mundo en transición. Las cosas solo son "mayoritariamente" como se ha anotado, pero no ocurren así siempre ni en todo lugar. Muchas están dejando de ser; otras empezando y la generalidad no se asienta con claridad y firmeza en una clara y nueva manera de ser. Veinte o treinta por ciento, quizá, de los trabajadores vive más cerca de 1950 o 1960 que del 2010. El avance en la educación, la capacitación y las remuneraciones, no se ha evaluado con paralelo júbilo, entre otras razones, porque junto con subir el piso del estándar de vida, subió el techo de las aspiraciones, o porque los beneficios no han llegado al "piso" en un porcentaje minoritario, pero todavía fuerte del contingente. Ese porcentaje no es un grupo identificado de personas que se debe reducir, sino una especie de "lugar social de miseria", adonde llegan y de donde

19 Caso empresa Titán. Presidente ejecutivo Sebastián Burr.

20 Una reciente estadística internacional lo sitúa en el $5^{\circ}$ lugar en el mundo. 
emigran constantemente personas, unas porque que caen en la miseria, desde una soportable modestia o pobreza dentro de la inmensa clase media chilena, y otras porque ingresan a ella, abandonando su tradición proletaria. Además, los términos de comparación no son los mismos hoy que hace cuarenta o cincuenta años. Hacia 1950 todo obrero deseaba que sus hijos fueran empleados particulares y, para ello, se aspiraba a que supieran leer y escribir. Hoy necesitan enseñanza media completa y puertas abiertas a la educación superior. Ya no existe la diferencia entre obreros y empleados, pero la educación superior es pagada y cara, aunque hay becados o auxilio de préstamos a largo plazo. En todo caso, el costo resulta excesivo para el nivel de remuneraciones de la gran clase media, que absorbió al grueso del proletariado de los años 30 o 40. Hacia 1940 había 6.402 alumnos universitarios, únicos aceptados como de nivel superior. En 1997 eran 380.604, provenientes de universidades, institutos profesionales y centros de formación técnica, todos de nivel superior, o sea, que habían completado la enseñanza media. En 2004 superaban los 400.000 . Mientras la población del país se multiplicó por cuatro en 70 años (4.000.000 a 16.000 .000 entre 1925 y 2005), la población de educación superior aumentó 60 veces $^{21}$ en 35 años. Por eso, el hoy acuciante tema del crédito universitario era tan impensable hacia los años treinta, cuarenta o cincuenta, como el que una máquina (el computador) pudiere enfermarse, infectada por un virus. En otro plano, mientras hacia 1940 morían más de 200 niños por 1000 nacidos vivos; ahora mueren al rededor de 8. O sea, en 1940 la mortalidad infantil era veinticinco veces mayor. Quizá por lo mismo, estos tremendos cambios de la "transición", privilegian los resultados estadísticos o cuantitativos, postergando valores y cualidades que no pueden ordenarse estadísticamente como el amor al prójimo, el patriotismo, la dignidad de cada persona humana o la realización de un anhelo vocacional.

7.7.2. El segundo asunto lo llamaría "el síndrome de Silicon Valley “, vale decir, la búsqueda de la eficacia y la libertad a cualquier precio. Se acaban la lealtad y el apego a la empresa propia, porque el objetivo es producir más, mejor, antes y a menor precio. Y si un trabajador, que durante veinte años laboró en una empresa, descubre un procedimiento para producir más barato y mejor que su empresa madre, tiene reconocido el derecho y "la moral" de irse e instalarse al frente su ex empresa y derrotarla. Lo llamativo no es que el trabajador se vaya e inicie la competencia, sino que eso entra en las nuevas reglas del juego libérrimo de Silicon Valley. Quien lo hace, ejercita su facultad de emprender y no es mirado como desertor o traidor. Pero se trata de una crisis de los conceptos tradicionales, que no sabemos a dónde nos llevará... Tal vez a producir más y mejor, pero al precio de la convivencia amistosa y solidaria. Quizá más cantidad de recursos, con menos calidad de vida.

7.7.3. Menos espectacular que el síndrome Silicon Valley, pero más universalizado y cercano a nosotros, es el outsourcing, que puede traducirse por la "externalización" y vinculado a ella, el trabajo en régimen de contratista y en empresas de trabajo transitorio (a los que se refiere la Ley $\mathrm{N}^{\circ}$ 20.123). Los meses inmediatos a la vigencia de esta normativa, dan cuenta de un debilitamiento del trabajo con asiento en una comunidad laboral de personas

21 Thayer ARTeAga, William. Texto y comentario del Código del Trabajo. Santiago, Chile: Editorial Jurídica de Chile, 2010, 652 pp. 
William Thayer Arteaga / Sobre la libertad sindical en el Chile de la posguerra

llamada empresa, cuyos fines y destino han de ser mirados como tarea común de cuantos pertenecen a ella. Estas diversas formas de distanciamiento psicológico, laboral y moral dentro de la empresa, renacen en la segunda mitad del siglo XX, cuando se buscaba avanzar desde un clima de lucha de clases otro de participación en el conocimiento y los resultados del esfuerzo individual (salario según productividad) y en el colectivo (participación en los resultados o utilidad), es una mala noticia. A través de una relación más armónica y beneficiosa, se aspiraba hacer realmente de la empresa una comunidad humana de trabajo, integrada por el afecto recíproco y los mejores frutos de la amistad y la paz, en lugar del recelo y el resentimiento clasista. Ahora reaparecen las sombras de un juego odioso de triunfo o derrota en algunos emblemáticos conflictos laborales. Como una especie de moderna diáspora económica, estructural y moral de los elementos que constituyen la empresa, está reviviendo con fuerza la vieja idea de una negociación colectiva "fuera de la empresa", estructurada en un nivel extra o supraempresarial, que suele llamarse, usando una expresión algo impropia y extemporánea: negociación colectiva por ramas de actividad". Esta opción arrecia con sugestiva fuerza y ostensibles manifestaciones de violencia, después de aprobada la Ley $\mathrm{N}^{\circ} 20.123$ (enero de 2007), que aspiraba a constituirse precisamente como una solución de consenso en cuanto a los trabajadores en régimen de subcontratación y de empresas suministradoras de trabajo transitorio. Por su actualidad y trascendencia, este tema no es propio de recuerdos personales, sino de reflexiones colectivas.

\section{LA EMPRESA COMUNIDAD HUMANA DE TRABAJO. CUESTIONES SUSCITADAS}

\subsection{La empresa: comunidad humana de trabajo.}

Opino con profunda convicción que la empresa comunidad humana de trabajo y Chile, como país, deben ser ubicados en el ámbito de la llamada cultura occidental ${ }^{22}$. Esta llegó a América en 1492 y a nuestra tierra, con Almagro, Valdivia y quienes "formaron la sociedad chilena", medio siglo después. Las relaciones laborales fueron regidas durante tres siglos por la minuciosa legislación de Indias. Fue el 15 de diciembre de 1563 cuando el Gobernador de Chile, don Pedro de Villagra aprobó y complementó en favor de los indios de Chile las "Ordenanzas para el buen gobierno, pacificación y defensa de Chile", que unos cuatro años antes había preparado el Licenciado Fernando de Santillán, Oidor de la Audiencia de Lima

8.2. La independencia política. Este trascendente suceso no puso fin al derecho indiano, pero inició su desaparición como tal, empezando, naturalmente, por el derecho público. Más tarde, la codificación de las leyes de la República de Chile (códigos civil, 1855; de comercio,1865; penal, 1874; Ley de Organización y Atribuciones de los Tribunales, 1875; código de minas, 1888; y de procedimiento civil, 1902, contemplaron disposiciones -interesantes, pero dispersas - de carácter laboral.

22 GODOY, Hernán (coord.). Chile en el ámbito de la cultura occidental. Santiago, Chile: Editorial Andrés Bello, 1987, passim. 
8.3. La cuestión social, Rerum Novarum y la Iglesia chilena. Circunstancias históricas que no es necesario rememorar aquí, condujeron al eminente pontífice León XIII, a publicar en 1891 su famosa encíclica Rerum Novarum, sobre la condición social de los obreros, documento que tuvo enorme repercusión en el mundo y, lógicamente, en Chile, cuya Constitución de 1833 reconocía al catolicismo como religión oficial del Estado. Esto asignaba, por lo mismo, a la Iglesia Católica una preponderante influencia política, social y cultural. Además, la Universidad Católica de Chile, recién fundada (1888), no tardó en hacerse eco de ese trascendental documento. Fue un joven egresado de sus aulas, Juan Enrique Concha Subercasseaux, quien primero asumió, en su tesis de graduación sobre "Cuestiones obreras" $(1899)^{23}$ la defensa de la doctrina y objetivos de la carta pontificia. Más tarde sería artífice principal de un proyecto de Código del Trabajo presentado en 1919 al Congreso por siete senadores conservadores. Este documento, en 34 artículos, se refería al mejoramiento de condiciones de trabajo, la formación de sindicatos únicos industriales (o de establecimiento) y una reglamentación de los conflictos de trabajo.

8.4. Alessandri Palma y las leyes laborales de 1924. Al imponerse Alessandri Palma en la disputada elección presidencial de 1920 -triunfó en definitiva por un voto sobre Barros Borgoño- encargó a Moisés Poblete Troncoso -como antes recordé- ${ }^{24}$ la preparación de un proyecto de Código del Trabajo, que, a través del difícil período histórico anteriormente reseñado, condujo a la precipitada aprobación de las leyes $\mathrm{N}^{\circ} 4.053$ (contrato de trabajo obrero); $\mathrm{N}^{\circ} 4.054$ (Caja de Seguro Obrero); $\mathrm{N}^{\circ} 4.055$ (accidentes del trabajo); $\mathrm{N}^{\circ} 4.056$ (tribunales de conciliación y arbitraje); $\mathrm{N}^{\circ} 4.057$ (organización sindical); $\mathrm{N}^{\circ} 4.058$ (cooperativas) y $\mathrm{N}^{\circ} 4.059$ (empleados particulares), desgajadas del proyecto que se discutió en el Congreso entre 1921 y 1924 y se refundió con modificaciones en el llamado "Código del Trabajo 1931", DFL N 178 de 13 de mayo de 1931.

8.5. La libertad sindical y el sindicato único obrero. La suerte corrida por el proyecto de Código en el Congreso no fue envidiable. El Presidente quería una rápida aprobación. No lo consiguió. Al contrario pasaron los años 1922, 1923 y parte de 1924 y no había humo blanco. Las relaciones entre Alessandri y el Senado eran entre malas y pésimas. Pero el obstáculo trascendía de lo político. Había un insoluble disenso técnico y social, que nos interesa especialmente en este análisis: el proyecto conservador de sindicato único de empresa chocaba frontalmente con el criterio de la OIT, que respaldaban el Presidente, sus asesores, y la bancada liberal, encabezada por don Eliodoro Yáñez, cuyo prestigio en su área, no le iba en zaga al de Juan Enrique Concha en las huestes conservadores. En mi opinión, el conflicto suscitado en 1919, solo vino a superarse en forma que puede estimarse definitiva, 80 años después, en 1999, cuando Chile inscribió en las Oficinas de la OIT de Ginebra, los instrumentos que certificaban la ratificación de los Convenios $\mathrm{N}^{\circ} 87$ y $\mathrm{N}^{\circ} 98$ de libertad sindical y negociación colectiva. Se había sellado el triunfo de la libertad sindical sobre el sindicato único, después de un largo proceso que explica, a su vez, los enredos, confusiones y malen-

23 V. en Anuario de la Universidad Católica; 1888-1900; Santiago, Chile: Imp. Cervantes, 1903, Tomo II, pp. 186-267.

$24 \mathrm{~V}, \mathrm{~N}$ os 1.5 y 1.6. 
tendidos con un proceso, vinculado pero diferente: la negociación por empresa y por ramas de actividad, tema preciso de este análisis.

8.6. Una larga y difícil convivencia entre dos opciones. Es un hecho que al irrumpir la revolución militar de septiembre de 1924, que forzó la aprobación de las Leyes 4.053 a 4.059, ya mencionadas, y en DFL $N^{\circ} 178$ de 1931, que las compendió, no se halló otra salida que aceptar convivencia de ambas opciones en nuestro naciente derecho colectivo ${ }^{25}$. Pero este no podía esquivar el problema legal, económico, social y cultural de la división de los asalariados entre una minoritaria porción de empleados particulares, una inmensa masa obrera asalariada y un tercer sector, también minoritario, pero muy influyente: los diferentes tipos de trabajadores del Estado.

El sindicato único obrero, mal llamado industrial, era de afiliación obligatoria para todos los obreros de la empresa. Contaba con el poderoso financiamiento que le otorgaban las cotizaciones sindicales -también obligatorias-, y la participación en las utilidades de la empresa que -como antes recordé- equivalía a un $6 \%$ de las remuneraciones pagadas a los obreros: un 3\% favorecía a los obreros individualmente considerados, y otro $3 \%$ al sindicato, lo cual fortalecía poderosamente su patrimonio. Como contrapartida, estos sindicatos "únicos" no podían "legalmente federarse ni confederarse". A la inversa, los sindicatos libres defendidos por la OIT y la bancada liberal, mal llamados profesionales, se ajustaban a los principios de la libertad sindical: eran de afiliación, desafiliación, federación y confederación libres; nadie podía obligar a afiliarse a ellos, ni impedir su retiro de los mismos. Pero debían vivir, sustancialmente, de las cuotas sociales pagadas por cada afiliado, porque no había una empresa a la que estuvieren necesariamente ligados, ni participación en las utilidades que incrementara el patrimonio sindical. Con todo, es de anotar que los afiliados podrían contarse por miles o cientos de miles, sin depender del número de trabajadores de la empresa, a menos que escogieran la única opción que los obligaba a ser pequeños y débiles en la inmensa mayoría de los casos: estructurarse como sindicatos profesionales de empresa, que fue precisamente lo que, a imitación de los sindicatos únicos obreros (industriales), prefirieron, salvo en casos interesantes, pero excepcionales (choferes, taxistas, peluqueros, estibadores, locutores de radio, electricistas, montadores de ascensores, vendedores ambulantes, vendedores viajeros, o viajantes, trabajadores de bombas bencineras, etc.). Ahora bien, como el Código de 1931 no permitía sindicarse a los trabajadores de las grandes empresas del Estado y el desarrollo fabril de aquellos años incipiente y escasas las grandes empresas, los sindicatos profesionales -minoritarios y pobres en cada empresa- vivían envidiando la "unicidad sindical" de los obreros, que les proporcionaba cuotas obligatorias y participación en las utilidades. Como si esta contradicción interna en la empresa fuera poco obstáculo para el sindicalismo, el "derecho individual del trabajo" creaba un conflicto letal con el derecho colectivo: cuando una actividad obrera se perfeccionaba y el obrero adquiría más altas calificación y productividad por el manejo de maquinaria sofisticada, perdía su condición de obrero y pasaba a ser empleado particular, con menos fuerza sindical, pero mejores condiciones económicas,

25 V. supra $n^{\circ} 1.6$ 
como lo narro como parte de mi experiencia personal en los números 2.1 y 2.2 de esta exposición.

8.7. La negociación sindical por empresa. El triunfo del sindicato único de empresa sobre el sindicato libre profesional, arrastró no solo a la negociación con la empresa en que se trabaja - lo que está bien- sino a la negociación "sindical" por empresa, que es asunto vinculado, pero distinto. Esta puede ser una buena, regular, mala o pésima opción, según las circunstancias, como trataré de explicar.

La empresa, comunidad humana, defendida como tal, desde Mater et Magistra hasta Centesimus Annus, por la Doctrina Social de la Iglesia, puede ser exitosa o frustrada, según sepa o no sepa armonizar adecuadamente la cuantía de los recursos materiales y el número, calificación y disposición a colaborar de sus trabajadores, con las exigencias propias o circunstanciales de su quehacer. Por ejemplo: una empresa siderúrgica no será jamás una microempresa, como pueden serlo una peluquería, una joyería, un taller de vulcanización o el de un zapatero remendón. En cambio la explotación de un yacimiento minero envuelve inevitables riesgos $\mathrm{u}$ opciones de fracaso o éxito. Los avances tecnológicos, a su vez, provocan fuertes modificaciones en la cantidad, calidad y especialidades de las ocupaciones, asunto por demás conocido y analizado. Pero lo que no se ha examinado debidamente es que la capacitación profesional y ocupacional y la consiguiente diferenciación de los ingresos por los cambios en la productividad, ha diversificado, achicado y multiplicado los colectivos negociadores en cada empresa. Una gran asamblea de trabajadores de escasa o nula calificación puede seguir clamando y presionando por aumentos generales y parejos de remuneraciones. Pero una asamblea donde concurren trabajadores de muy diferentes productividad, naturalmente generará diversidad de intereses, según el grado de calificación. Los trabajadores altamente productivos, preferirán las remuneraciones que valoren su mayor productividad. Los de baja o nula calificación pugnarán por la elevación de los mínimos o los aumentos promediados, que castigan a los altamente productivos y favorecen a los de menor calificación. Esto conspira en contra de los grandes colectivos negociadores, pero no en contra de los grandes sindicatos, que deben respaldar a todos los miembros, procurando que sus remuneraciones estén más cerca del techo que del piso dentro de su respectiva especialidad y de lo que sea capaz de asignar la situación de cada empresa. Más aún, en ocasiones será preferible -y así deberá aconsejarlo el respectivo sindicato- negociar individualmente, si no hubiere un grupo similar apto para constituir un colectivo laboral. Si el sindicato no reconociere la realidad de estas situaciones ("principio de la realidad"), perderá como afiliados a los trabajadores de más alta calificación.

\section{REFLEXION FINAL}

En los años cincuenta, como abogado de la Confederación de Trabajadores del Cobre, participé activamente en la elaboración del Estatuto de los Trabajadores del Cobre. No se fundaba en la libertad sindical plena, pero se aproximaba a ella. Se aceptó la federación y confederación de sindicatos industriales; se abrió la negociación por "centros de trabajo" 
de cada empresa; se extendió a 15 meses la duración de los contratos colectivos de trabajo; se establecieron la iniciación de la negociación colectiva 45 días antes del vencimiento del respectivo contrato y el principio de votar la huelga como una opción entre la mejor oferta o la paralización de labores. Diez años más tarde, como Ministro del Trabajo del presidente Frei Montalva, propuse la plena libertad sindical, proyecto que no tuvo respaldo político ni social. No era aún la hora de la libertad sindical y primaba como un ídolo, el sindicato único de empresa. Debí contentarme con reducir mis esfuerzos a establecer la libertad sindical, conforme a los principios de la OIT, en el sector campesino (Ley $\mathrm{N}^{\circ} 16.625$ de 1967). A fines de los años setenta, colaboraré en la dictación de las leyes del Plan Laboral, que abrían camino a la libertad sindical y terminaban con el sindicato único de empresa. La explicación de esta "apertura" hacia la libertad sindical, en mi opinión, no radica en que fuera impuesta por un Gobierno autoritario: la clave estuvo en que se legislaba "para regir después" del gobierno militar. Así el mismo Aylwin, que en 1966 negó el pase a la libertad sindical como presidente del PDC, en 1991, como Presidente de Chile, puso su firma a la Ley $N^{\circ} 19.069$ que ratificó, con algunos perfeccionamientos, la libertad sindical e hizo posible ratificar los Convenios $\mathrm{N}^{\circ} 87$ y N$^{\circ} 98$ de la OIT. 